University of Nebraska - Lincoln

DigitalCommons@University of Nebraska - Lincoln

1998

\title{
Dispersal and Longevity of Mass-Released, Sterilized Mexican Fruit Flies (Diptera: Tephritidae)
}

Donald B. Thomas

USDA-ARS

Jesus Loera-Gallardo

Instituto Nacional de Investigaciones Forestales y Agropecuarios

Follow this and additional works at: https://digitalcommons.unl.edu/entomologyother

Part of the Entomology Commons

Thomas, Donald B. and Loera-Gallardo, Jesus, "Dispersal and Longevity of Mass-Released, Sterilized Mexican Fruit Flies (Diptera: Tephritidae)" (1998). Entomology Papers from Other Sources. 56.

https://digitalcommons.unl.edu/entomologyother/56

This Article is brought to you for free and open access by the Entomology Collections, Miscellaneous at DigitalCommons@University of Nebraska - Lincoln. It has been accepted for inclusion in Entomology Papers from Other Sources by an authorized administrator of DigitalCommons@University of Nebraska - Lincoln. 
Biological Control

\title{
Dispersal and Longevity of Mass-Released, Sterilized Mexican Fruit Flies (Diptera: Tephritidae)
}

\author{
DONALD B. THOMAS ${ }^{1}$ AND JESUS LOERA-GALLARDO ${ }^{2}$
}

\begin{abstract}
Environ. Entomol. 27(4): 1045-1052 (1998)
ABSTRACT Trap-back experiments using McPhail traps were conducted to study dispersal and longevity of mass-released, sterile Mexican fruit flies, Anastrepha ludens (Loew). The flies were released at 3 ecologically different sites in northern Mexico. Some flies were recaptured up to $9 \mathrm{~km}$ from the release point. However, standard distance was estimated using a regression model that indicated $240 \mathrm{~m}$ was the typical dispersal distance. The life expectancy of the released flies from the time of release varied from 5 to $10 \mathrm{~d}$. Greatest longevity, up to $22 \mathrm{wk}$, occurred during the winter months.
\end{abstract}

KEY WORDS Anastrepha ludens, fruit fly, dispersal, longevity, sterile insect technique

MEXICAN FRUT Fly, Anastrepha ludens (Loew), is a major pest of citrus in Mexico, Belize, Guatemala, and the lower Rio Grande valley of Texas. Populations of this pest are suppressed, with varying degrees of success, by a program of mass releases of radiosterilized flies in the citrus- producing regions (Williamson and Hart 1989). For the sterile insect technique to be efficacious there has to be a higher proportion of sterile:fertile contacts than fertile:fertile contacts (Lawson 1967). It is believed that high overflooding ratios, measured by the proportion of steriles to fertiles in trap-back studies, provide evidence that such proportions are achieved (Holler and Harris 1993). For example, in 1983, the lst year of the suppression effort in southern Texas, a total of $140.5 \times 10^{6}$ sterile flies was released. With a density of $2 \mathrm{McPhail}$ traps per square kilometer the monitoring program recaptured $0.15 \%$ of the released sterile flies. A total of 509 feral flies also was captured, giving an overflooding ratio of 409:1 (Holler et al. 1984). The sterile release program has been applied continuously from 1983 to the present, yet a wild Mexican fruit fly population persists in the lower Rio Grande valley. In 1995 a total of 614 wild flies was captured by the USDA-APHIS monitoring program.

The scientifically sound implementation of the sterile insect technique requires basic information on the performance of the mass-released insects. The sterile insects must persist at the target site to be effective as agents of control. Basic questions are, how long do the flies live after they are released and how far do they disperse? Such information is necessary for determining the frequency with which releases should be made and the distance between release points.

\footnotetext{
Subtropical Agricultural Research Center, USDA-ARS, 2301 South International Boulevard, Weslaco, TX 78596.

${ }^{2}$ Instituto Nacional de Investigaciones Forestales y Agropecuarios Campo Experimental, Rio Bravo, Tamaulipas, Mexico.
}

Trap-back studies have been the traditional method by which such information is obtained. The classic trap-back study of the Mexican fruit fly is that of Shaw et al. (1967) conducted in the states of Morelos, Nuevo Leon, and Baja California, Mexico. They reported recapture of a sterile fly 12 mo after release and a recapture of another fly $37 \mathrm{~km}$ from the release point. But, program managers need to know the longevity and dispersal radius of typical, not exceptional flies. Shaw et al. (1967) stated that 5-8 km was normal and 8 mo was the average age of recaptured flies. However, their study was designed to measure long-distance dispersal. In their Morelos study, the nearest traps were $5 \mathrm{~km}$ from the release point and only 8 flies out of 750,000 released were recaptured. In their Nuevo Leon study, the nearest traps were $7 \mathrm{~km}$ from the release point and only 2 out of $1.1 \times 10^{6}$ released flies were recaptured.

A very different trap-back strategy was used by Baker et al. (1986) and Baker and Chan (1991) in Chiapas, Mexico. However, their limited experimentation was incidental to a larger study of the Mediterranean fruit fly, Ceratitis capitata (Wiedemann); the trapped area was only $90 \mathrm{~m}$ in radius and the duration of the study was only $4 \mathrm{~d}$. There is, therefore, a paucity of definitive information on dispersal and longevity of sterile, released Mexican fruit flies. We present data on sterile fly releases at 3 ecologically different sites in northern Mexico. The implications of our findings to the application of the sterile insect technique to suppress Mexican fruit fly populations are discussed.

\section{Materials and Methods}

The flies used in these studies were reared at the USDA-APHIS-PPQ Mexican fruit fly production plant at Mission, TX, the same source of flies used for the suppression program in Texas. The flies were sterilized by exposing the late puparial stage to $70-116 \mathrm{~Gy}$ 
from a Cesium-137 source. The irradiated puparia were held in a plastic, screened emergence container (16-liter capacity) until eclosion was complete (adults eclose over a 3 -d period). The container was provided with a gelled slab containing fructose, water, and yeast hydrolysate (Martinez et al. 1987). Following the last day of emergence the flies were transported by airconditioned vehicle to the study sites in Mexico where the container was opened and the flies allowed to escape. Any remaining, nonflying insects were dislodged by vigorous shaking of the container. Releases were made at monthly intervals and in all replicates the number of flies per release was 25,000. The flies were marked with a different color fluorescent dye (Schroeder et al. 1972) each month so that the released flies could be distinguished from feral flies and among the different releases. McPhail traps (Gempler's, Mt. Horeb, WI) were operated continuously using water and torula yeast as the attractant. These traps were serviced weekly. A recording hygrothermograph (Model 5-207-W, Belfort, Baltimore, MD) and rain gauge were operated continuously at each release site. The eastern premontane slopes of southern Nuevo Leon, where these experiments took place, have a subtropical climate characterized by rainy summers and mild winters (Arbingast et al. 1975).

The 1st experiment was conducted from March to December 1994 at Santa Rosa Canyon, Nuevo Leon, Mexico, directly east of the town of Iturbide. This site was a steep-sloped mountain canyon with an intermittent stream. The release point $(1,040 \mathrm{~m}$ in elevation) was at the midpoint of a trap transect, $19 \mathrm{~km}$ in length, that followed the riparian habitat of the streambed. The dominant vegetation in this gallery forest was yellow chapote, Sargentia greggi (S. Wats.) (Rutaceae), the native host of the Mexican fruit fly (Plummer et al. 1941). This study site is described in more detail by Thomas (1993). Each trap site consisted of 5 McPhail traps in separate but adjacent chapote trees. Nine trap sites were operated continuously, including 1 adjacent to $(50-100 \mathrm{~m})$ the release point, with 4 arrayed to the east and 4 to the west. The distances were 1.5, 3.0,5.0, and $9.0 \mathrm{~km}$ east; and 5.0, 7.0, 9.0 , and $10.0 \mathrm{~km}$ to the west. The trap sites were selected for their density of yellow chapote and for accessibility.

A 2nd experiment was conducted from February to December 1996 along the Linares River, $\approx 10 \mathrm{~km}$ southwest of the town of Linares, Nuevo Leon. This site had a meandering river coursing through relatively level terrain at an elevation of $450 \mathrm{~m}$. A gallery forest of Mexican ash (Fraxinus berlandieriana A. de Candolle) and sycamore (Platanus occidentalis L.) dominated the banks of the river along with dense mots of yellow chapote. Citrus groves (mainly 'Valencia' orange) flanked the river at irregular intervals. The release point was in a mot of yellow chapote next to the river with the 1 st set of 5 traps $\approx 100 \mathrm{~m}$ away. The 2nd set of 5 traps was placed in an orange grove next to the river $300 \mathrm{~m}$ upstream from the release point. A 3 rd set of traps was placed in the river bottom $1 \mathrm{~km}$ downstream from the release point. A 4 th set of traps

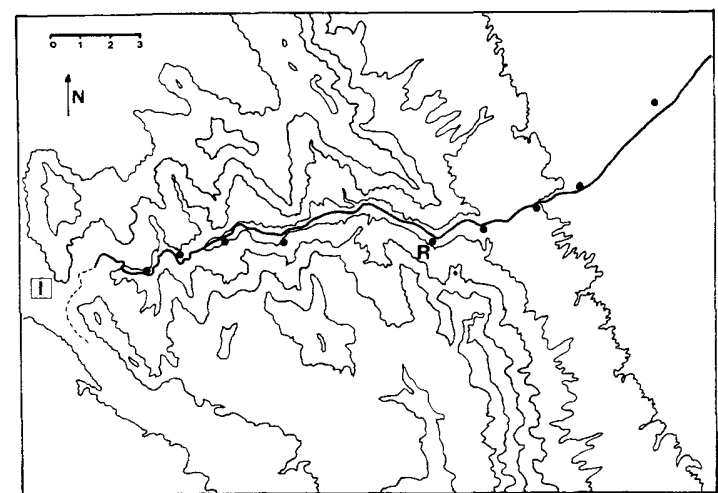

Fig. 1. Distribution of trap stations along the Santa Rosa River. R, release point. I, Iturbide (town). Contour lines are 300 -m intervals redrawn from topographic maps available from the Institute National de Estadistica, Geografia y Informativa.

was placed in an orange grove adjacent to the river 1 $\mathrm{km}$ downstream from the release point. The 5 th set of traps was placed in a small orange grove $1 \mathrm{~km}$ overland away from the river and the release point. There were no intervening citrus groves between these trap sites and the release point.

A 3rd study was conducted from March to December 1995 in a large (180 ha) commercial Valencia orange grove near Rio Bravo, Tamaulipas, Mexico (23 $m$ in elevation). Flies were released at the center of the grove with 52 traps set at various distances throughout the grove extending from 50 to $1,700 \mathrm{~m}$ from the release point. To achieve a degree of uniformity among traps, all traps were placed in the penultimate tree of its respective row. Aluja (1994) notes that traps in the periphery of groves tend to catch more flies. This grove was surrounded by row crop agriculture for several kilometers in all directions and the grove was bordered on all sides by irrigation or drainage canal. Salt cedar, Tamarix rammossima Ledebour, and catclaw, Acacia berlandieri Bentham, bordered these canals and were the only trees in the area aside from the grove of citrus.

Statistics. Dispersion and longevity were modeled by least squares regression and goodness-of-fit to the regression line measured by the coefficient of determination, residual mean square, and single classification analysis of variance (ANOVA) (Sokal and Rohlf 1973). The probability of the $F$ value from ANOVA was computed with the software program FPROB (Speakeasy Computing 1987).

\section{Results and Discussion}

Long-Range Dispersal. Of the one-quarter of a million flies released at Santa Rosa canyon in 1994, 1,766 $(0.7 \%)$ were recaptured. This experiment was designed to determine the frequency of longer-range dispersal. The topography naturally confined the movement of the flies to an east-west orientation, following the river bottom (Fig. 1). Nevertheless, the 
Table 1. Recaptures at Santa Rosa canyon as a function of distance and direction from the release point at Rio Seco

\begin{tabular}{lcr}
\hline Trap station & Distance, Km & Recaptures \\
\hline Rio Seco & $0.1 \mathrm{E} \mathrm{\&} \mathrm{W}$ & 1,731 \\
La Palma & $1.5 \mathrm{E}$ & 3 \\
El Cañon & $3.0 \mathrm{E}$ & 10 \\
El Puente & $5.0 \mathrm{~W}$ & 6 \\
Le Crucita & $5.0 \mathrm{E}$ & 0 \\
El Rancho & $7.0 \mathrm{~W}$ & 14 \\
Penultimo & $9.0 \mathrm{~W}$ & 2 \\
Ojo de Agua & $9.0 \mathrm{E}$ & 0 \\
Iturbide & $10.0 \mathrm{~W}$ & 0 \\
\hline
\end{tabular}

Configuration of trap sites shown in Fig. 1.

vast majority of the recaptures, $98 \%$ (all but 35 flies), was in the traps adjacent $(<100 \mathrm{~m})$ to the release point. Notably, the trap-back numbers were not a strict function of distance. If dispersal from the release point was by a process of simple diffusion, one would expect a descending rate of recapture with distance, but this was not the case. The data in Table 1 show that more flies were recaptured at El Cañon, $3 \mathrm{~km}$ to the east, than at La Palma, only $1.5 \mathrm{~km}$ to the east. Likewise, more flies were recaptured at El Rancho, $7 \mathrm{~km}$ to the west, than at El Puente, $5 \mathrm{~km}$ to the west. Although the actual numbers are small, the clustering of the recapture numbers along the transect suggests the effects of contagion. Although chapote occurred at all of the trap sites, the 2 sites at El Cañon and at El Rancho were the largest mots of chapote in the canyon. Thus, it may be that the dispersing flies were attracted to and remained in these mots and this could account for the contagion in the data. If so, the incidence of long-distance dispersal may be overrepresented in the data. Regardless, movements of distances on the order of several kilometers by the sterile flies is adventitious. Interestingly, the greatest distances traveled by the flies and the most extended recapture times occurred over the winter. Two marked flies released on 11 October were recaptured on 9 January at a trap site $9 \mathrm{~km}$ upstream from the release point. One fly released in September was recaptured in February (157 d later) $<100 \mathrm{~m}$ from where it was released. Monitors of the suppression program in southern Texas also report that persistence of the sterile, released flies is greater in winter than in summer ( $\mathrm{J}$. Worley, personal communication).

Of the 275,000 flies released at the Linares River site in $1996,1,926(0.7 \%)$, were recaptured. All flies were recaptured at the 2 sets of traps nearest the release point, one set $\approx 100 \mathrm{~m}$ distant $(\mathrm{n}=1,795)$ and the other in a nearby orchard $\approx 300$ m distant $(n=131)$. No flies were recaptured at any of the 3 sets of traps $1 \mathrm{~km}$ distant from the release point. Longevity was similar to that of the previous experiment with recaptures up to $11 \mathrm{wk}$ after release, the longest ( $78 \mathrm{~d}$ ) occurring during the winter.

The results of this and the previous experiment suggest that sterile flies do not regularly disperse the long distances reported by Shaw et al. (1967). Shaw et al. (1967) released their flies in open, brushy country.
The release point for the studies described herein included water, shade, and the native host plant. If dispersal is related to appetitive behavior then the flies in our experiments may have been less motivated to disperse than those in the experiments of Shaw et al. (1967).

Standard Distance. Our 3rd experiment was conducted within the confines of a large orange grove. The flies were released at the center of the grove with the traps scattered at variable distances out to $1,700 \mathrm{~m}$. Of the 275,000 flies released, 2,770 (1\%) were recaptured. The recaptures extended to $9 \mathrm{wk}$, somewhat less than in the previous experiments. Also, the most extended recapture time was for a fly released in July rather than in winter as in the other experiments. The smaller trapping distances used in this study allow more precise measurement of the dispersal of the released flies. Fig. 2 shows the dimensions of the Rio Bravo grove and the resulting recapture density distribution.

Dispersion was measured by regressing distance against trap success. If dispersal from the release point occurred by simple diffusion in Brownian fashion, the distribution of recaptures around the release point would follow the half-normal curve. In their classic study of dispersal in Drosophila pseudoobscura Frolowa, Dobzhansky and Wright (1943) showed that the distribution of recaptures was strongly leptokurtic. The leptokurtosis in the trap-back data resulted from more flies remaining at the release point and more flies dispersing long distances than would be predicted by the diffusion model. Contrary to expectations of random diffusion (Rudd and Gandour, 1985) all trap-back studies of fly dispersal reviewed by Freeman (1977) and Taylor (1978) exhibited the same leptokurtic de-

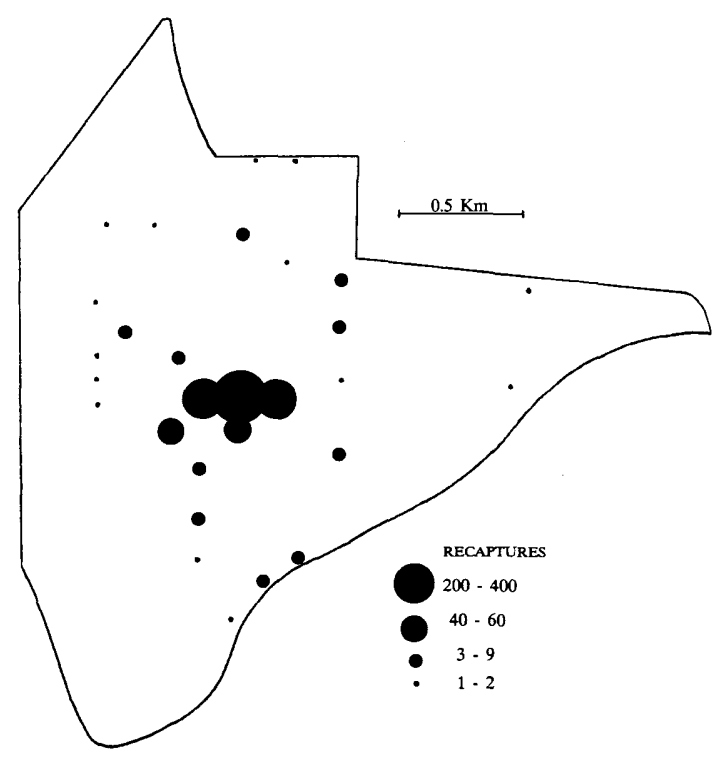

Fig. 2. Recapture density distribution for the Rio Bravo orange grove. The release point was near the center of the largest black dot. 
Table 2. Estimation of standard distance in Rio Bravo releases (1995) by using regression of flies per trap (Y) against distance ( $x$ ): $\ln Y=17.53315-6.07868 \log X$

\begin{tabular}{|c|c|c|c|c|c|c|c|}
\hline 1 & 1 & 50 & 1.6990 & 7.2087 & $1,351.0$ & $1,351.0$ & $3,377,500$ \\
\hline 3 & 5 & 250 & 2.3979 & 2.9616 & 19.3 & 96.5 & $6,031,250$ \\
\hline 4 & 7 & $3 \check{0} 0$ & 2.5441 & 2.0732 & 7.9 & 55.3 & $6,774,250$ \\
\hline 5 & 9 & 450 & 2.6532 & 1.4102 & 4.1 & 36.9 & $7,472,250$ \\
\hline 8 & 15 & 750 & 2.8751 & 0.0617 & 1.07 & 16.0 & $9,000,000$ \\
\hline 9 & 17 & 850 & 2.9294 & -0.2682 & 0.76 & 12.9 & $9,320,250$ \\
\hline 10 & 19 & 950 & 2.9777 & -0.5617 & 0.57 & 10.8 & $9,747,000$ \\
\hline 11 & 21 & 1,050 & 3.0212 & -0.8261 & 0.44 & 9.2 & $10,143,000$ \\
\hline 12 & 23 & $1,1 \tilde{5} 0$ & 3.0607 & -1.0661 & 0.34 & 7.8 & $10,315,500$ \\
\hline 13 & 25 & 1,250 & 3.0969 & -1.2861 & 0.27 & 6.8 & $10,625,000$ \\
\hline
\end{tabular}

$r^{2}=0.9092 ;$ resMS $=0.6623 ; F=100.11 ; \mathrm{df}=1,11$.

parture from the normal distribution. Baker and Chan (1991), studying the Mediterranean fruit fly, reported that leptokurtosis diminishes with time; however, this result may be attributable to the small size of their trap area (only $90 \mathrm{~m}$ in radius). In a more extensive study, Plant and Cunningham (1991) found dispersal essentially ceased after $3 \mathrm{~d}$ but leptokurtosis was marked. Dobzhansky and Wright (1943) explained the leptokurtic dispersion pattern as arising from appetitive dispersal. Flies finding their requisite resources near the release point tended to stay in the immediate vicinity, whereas the deprived flies tended to move a substantial distance from the release point.

Inasmuch as the recaptures are not normally distributed, mean trap distance is not an adequate measure of dispersal. Some investigators (Hawkes 1972, Freeman 1977, Carey 1993) report an index of dispersion called the standard distance that is approximately equivalent to the median distance. It is calculated by treating each individual recapture displacement as a deviation from the release point, which is assumed to be the center of the distribution. Thus, standard distance is statistically equivalent to the standard deviation of the dispersion.

In the study by Dobzhansky and Wright (1943) the traps were arrayed in a linear transect. Therefore, an adjustment to the data was necessary for trap-density dilution. They simply multiplied the captures by $\pi r^{2}$. When traps are distributed at regular intervals, no adjustment for trap density dilution is necessary. However, such a trapping regime is generally limited in practice to a relatively small area, as was the case in the study of Baker et al. (1986). For the larger areas that are necessary for coverage of most dispersion such designs are impractical. In a study of the Queensland fruit fly, Bactrocera tryoni (Froggatt) Fletcher (1974), and the olive fly, Bactrocera oleae (Gmelin) (Fletcher and Economopoulos 1976), traps were dispersed at selected distances and the area of annuli radiating out from the release point was used to adjust for trap density dilution. We adapted the same methodology by using annuli of $100-\mathrm{m}$ widths. Recapture data are first expressed as the number of flies per trap within an annulus and this number is then multiplied by the area of the annulus (Table 2). The calculations are simplified by using $\pi$-ha as the unit area of measure. This is because the area of the 100-m-radius circle at the center of the distribution is $1 \pi$-ha. The area of the 1st annulus is $3 \pi$-ha or 3 times the area of the central circle. The area of each annulus can be expressed in whole numbers as units of $\pi$-ha and density as the number of flies per annulus. Standard distance can then be calculated directly from this data, or the data can be fit to a regression equation from which a smoothed distribution can be generated and the standard distance calculated from the regression data. Both methods are provided herein for comparison. Using the actual data without regression the standard distance for the Rio Bravo data was calculated as $250 \mathrm{~m}$. However, the reliability of this estimate might be questioned inasmuch as the $r^{2}$ value was only 0.337 .

Several regression models of insect dispersion have been proposed; however, Taylor $(1978,1980)$ demonstrated that all equations are special cases of a general exponential equation

$$
\operatorname{Ln} Y=\mathrm{a}+\mathrm{b} X^{c}
$$

where $X$ is the recapture distance and $Y$ is the number of individuals captured at that distance. The exponent $c$, also known as the Weibull function, varies from +4 to -4 and can be solved iteratively for any given data set. The best value of $c$ is the one that gives the highest coefficient of determination $\left(r^{2}\right)$, residual mean square, and $F$-ratio. For the Rio Bravo data the value of $c$ giving the best fit was 0.2 with an $r^{2}$ of 0.92 , a residual mean square of 0.578 , and an $F$-ratio of 116.13 $\left(P=0.798 \times 10^{-6}\right)$. The standard distance calculates to $240 \mathrm{~m}$ with this equation. However, in cases where the value of $c$ approaches zero the Weibull distribution becomes assymmetrical with respect to the residual variance (Taylor 1978). For example, with the Rio Bravo data set, peak $r^{2}$ and minimal residual variances 


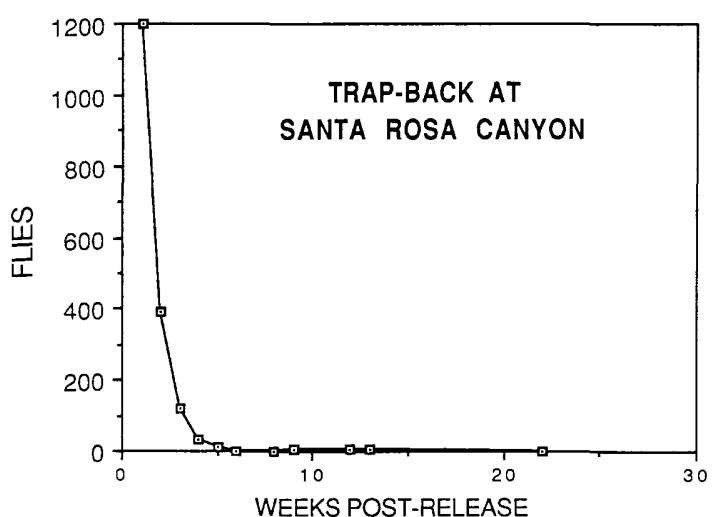

Fig. 3. Recaptures as a function of time after release at Santa Rosa canyon.

also occurred at $c=0.02$ and 0.002 . In such cases the Gompertz equation, also known as the complementary log-log, can be substituted without significant loss of mathematical precision

$$
\operatorname{Ln} Y=\mathrm{a}+\mathrm{b} \log X .
$$

The Gompertz equation has the advantage of greater biological justification inasmuch as many biological processes are log-normal (Wadley 1957). The application of the Gompertz equation to the data results in a standard distance measurement of $236 \mathrm{~m}$ (Table 2) with an $r^{2}$ of 0.91 , a residual mean square of 0.662 , and an $F$-ratio of $100.11\left(P=0.735 \times 10^{-6}\right)$.

It is noteworthy that the difference between the calculated standard distance and the regression estimated standard distance was small. The advantage of the regression equation is that it can be used to estimate the expected fly density for any given distance from the release point. A manager of a sterile release program might ask the question, what are the chances that a wild, fertile fly in a citrus tree $1 \mathrm{~km}$ from a release point will encounter a sterile fly in the same tree? The regression model can be used to answer this question.

Longevity. The rate of dispersion is inextricably entwined with survival rate. The longer the flies live, the farther they are likely to be found from the point of release. Thus, disappearance of insects from a release site may be due to death or to emigration from the area. Where emigration is minimal, we attribute the decline in recaptures to mortality. Although individual longevity records are interesting, the mean life span is of greater significance for population studies and of greater relevance for the management of suppression programs. It has been known since the classic studies of Deevey (1947) that insect survival curves are exponential (Deevey's type III), and this is true for the Mexican fruit fly as well (Fig. 3). An exponential regression equation with the Weibull function $c$ as in equation 1 can be used to describe survival (Pinder et al. 1978). The equation is used to generate daily survival rates that can be arrayed in a life table for the calculation of the mean life span following Carey (1993)

$$
\text { Mean life expectancy }\left(e_{x}\right)=\Sigma(l x-[d x / 2]) \text {, }
$$

where $l x$ is the proportion of the flies alive at the beginning of each week and $d x$ is the death rate or proportion of flies that die each week $(\Sigma l x=1)$. For the data from the Linares River experiment the equation which describes survival rate is

$$
\operatorname{Ln} Y=7.91-0.95 X^{0.88},
$$

where $Y$ is the number of flies captured per week and $X$ is time in weeks after release. The $r^{2}$ for this equation is 0.95 , the residual mean square is 0.312 , and the $F$-ratio is $182.7\left(P=0.277 \times 10^{-6}\right)$. The life table generated by this equation is shown in Table 3 . The mean life expectancy from the time of release (flies are $3 \pm 1 \mathrm{~d}$ old at release) during this experiment was calculated to be $9.85 \mathrm{~d}$. By comparison, flies held in the laboratory under optimal conditions (constant $28^{\circ} \mathrm{C}$, $75 \% \mathrm{RH}$ ) have a mean life expectancy of $17.3 \mathrm{~d}$ (Celedonio-Hurtado et al. 1988). Because the survival curve is exponential, these life expectancy estimates are equivalent to a half-life. For the Santa Rosa canyon experiment the mean life expectancy was calculated to be $8.0 \mathrm{~d}$ even though one exceptional fly was captured 22 wk after release. The $r^{2}$ of the survivorship curve equation was 0.85 , the residual mean square was 0.811 , and the $F$-ratio was $63.14\left(P=0.696 \times 10^{-5}\right)$. For the Rio Bravo orange grove releases, mean life expectancy was only $4.8 \mathrm{~d}$, half that of the releases into native vegetation. The $r^{2}$ of the survival curve equation was 0.98 , the residual mean square was 0.137 , and the $F$-ratio was $386.6\left(P=1.122 \times 10^{-6}\right)$. The shorter life span in this situation may be attributable to a combination of factors, including a lack of free water at the release site, less shade, and higher ambient temperatures due to the location being at a higher latitude and at a lower elevation. Inasmuch as the male Mexican fruit fly does not attempt mating before $4 \mathrm{~d}$ of age (Dickens et al. 1982), it may be worthwhile holding the flies until at least that age prior to delivery at the release sites given the short life expectancy once they are released.

Weather and Fly Captures. Intuitively, one would expect that weather at the time of release and over the days immediately succeeding would be a strong de-

Table 3. Life expectancy calculations in Linares River releases (1996). Life table frequencies generated by $\ln (Y)=7.91-$ $0.95 X^{.88}$, where $L x=1 x-(d x / 2)$

\begin{tabular}{rrrrrrc}
\hline Age & $\ln \mathrm{Y}$ & \multicolumn{1}{c}{$Y$} & \multicolumn{1}{c}{$\mathrm{L}$} & \multicolumn{1}{c}{$l x$} & $d x$ & $L x$ \\
\hline 1 & 6.960 & 1,054 & 1,972 & 1.0000 & 0.5345 & 0.733 \\
2 & 6.162 & 475 & 918 & 0.4655 & 0.2409 & 0.341 \\
3 & 5.412 & 224 & 443 & 0.2246 & 0.1136 & 0.168 \\
4 & 4.692 & 109 & 219 & 0.1111 & 0.0553 & 0.083 \\
5 & 3.994 & 54 & 110 & 0.0558 & 0.0274 & 0.042 \\
6 & 3.313 & 28 & 56 & 0.0284 & 0.0142 & 0.021 \\
7 & 2.645 & 14 & 28 & 0.0142 & 0.0071 & 0.011 \\
8 & 1.988 & 7 & 14 & 0.0071 & 0.0035 & 0.005 \\
9 & 1.342 & 4 & 7 & 0.0035 & 0.0020 & 0.002 \\
10 & 0.704 & 2 & 3 & 0.0015 & 0.0010 & 0.001 \\
11 & 0.073 & 1 & 1 & 0.0005 & 0.0005 & 0.000 \\
& \multicolumn{7}{c}{ Life expectancy $=\Sigma L x=1.407 \mathrm{wk}=9.85 \mathrm{~d}$} & \\
\hline
\end{tabular}


Table 4. Coefficients of determination $\left(r^{2}\right), F$-ratios, and probability $(P)$ for regressions of fly captures against rainfall, temperature $(T)$, and temperature stress in degree-days $\left({ }^{\circ} \mathrm{D}\right)$ calculated as the sum of deviations from 29 and $19^{\circ} \mathrm{C} / \mathrm{d}$

\begin{tabular}{|c|c|c|c|c|c|c|c|c|c|}
\hline \multirow{2}{*}{ Weather } & \multicolumn{3}{|c|}{$1994^{*}$} & \multicolumn{3}{|c|}{$1995^{* *}$} & \multicolumn{3}{|c|}{$1996^{* *}$} \\
\hline & $r^{2}$ & $F$ & $p$ & $r^{2}$ & $F$ & $p$ & $r^{2}$ & $F$ & $p$ \\
\hline Max temp & 0.439 & 6.072 & 0.036 & 0.013 & 0.128 & 0.728 & 0.004 & 0.040 & 0.845 \\
\hline Min. temp & 0.004 & 0.036 & 0.854 & 0.004 & 0.037 & 0.851 & 0.145 & 1.691 & 0.222 \\
\hline Mean temp & 0.011 & 0.103 & 0.756 & 0.012 & 0.120 & 0.736 & 0.117 & 1.334 & 0.275 \\
\hline${ }^{\circ} \mathrm{D}$ & 0.054 & 0.511 & 0.493 & 0.057 & 0.607 & 0.454 & 0.138 & 1.645 & 0.215 \\
\hline Rain & 0.100 & 1.005 & 0.342 & $0.654^{*}$ & 18.901 & 0.001 & $0.402 *$ & 6.550 & 0.028 \\
\hline
\end{tabular}

In each case the weather and capture data were from the lst wk after release for each replicate.

$*$, Degrees of freedom for ANOVA $=1,9 . * *$, Degrees of freedom for ANOVA $=1,10$.

terminant of survival of the factory-reared flies confronted with the rigors of the natural environment. However, we were able to find only weak correlations among weather variables and trap-back success. Using least squares linear regression, we computed coefficients of determination for the numbers of flies trapped during the 1 st wk after release against rainfall, maximum temperature, and minimum temperature. The coefficients tabulated in Table 4 demonstrate that these parameters were of little value for predicting trap success. Because any relationship between temperature and survivorship or activity would probably not be linear, an index of temperature stress was calculated. The index was calculated using the degreeday method (Thomas 1997) except that instead of using a single base temperature threshold, the degreedays were calculated as the sum of the daily accumulation in excess of 2 comfort points. Thus (maximum $-29)+(19-$ minimum $)$ in degrees centigrade for the $7 \mathrm{~d}$ after release will equal degree-days. Nonetheless, no relationship between temperature stress and trap-success was demonstrable. In 1 yr (1994), there was a weak but statistically significant correlation between maximum temperatures and trap success. In the succeeding $2 \mathrm{yr}$ rainfall was significantly correlated with fly captures whereas temperature was not. The inconsistency in the results and the weakness in the correlations seems to be an inherent characteristic of MacPhail trap data (McPhail 1937). Eskafi (1988), studying wild populations of tephritids in Guatemala, was unable to correlate the numbers of Mexican fruit flies in traps with temperature, humidity, or rainfall. Similarly, Celedonio-Hurtado et al. (1995) and Aluja et al. (1996) were unable to find a correlation between weather and trap success.

Sterile Insect Technique. To be efficacious, sterile insects must be released at a frequency and density to ensure that most of the copulations involving fertile individuals include sterile partners. Although these experiments show that individual radiosterilized Mexican fruit flies may live up to $5 \mathrm{mo}$ and disperse up to $9 \mathrm{~km}$ from the point of release, the typical fly lives only a short time after release (5-10 d) and disperses only a short distance $(\approx 1 / 4 \mathrm{~km})$. In populational terms, $94 \%$ ( 3 SD) of the flies are dead within 1 mo and remain within $1 \mathrm{~km}$ of the point of release. Our results were very similar to those reported by Plant and Cunningham (1991) for the Mediterranean fruit fly. In their study the average distance flown over the maximum life span of the cohort was $<300 \mathrm{~m}$ with less than half of the released flies surviving $>3 \mathrm{~d}$. Under these circumstances, relatively frequent releases with aided dispersal would be more effective than massive point releases. Plant and Cunningham (1991) recommended that releases should be made at points or along lines of no more than $250 \mathrm{~m}$ spacing. They argued that compensating for wider spacing by increasing the release rate would be inefficient because of the negatively exponential survival rate. Nevertheless, current releases of sterile fruit flies (both Mediterranean and Mexican fruit flies) are performed by aircraft with standardized flight lanes of $320 \mathrm{~m}$ spacing (J. Worley, personal communication). For practical reasons the actual method of release often depends on the circumstances. Ground releases are sometimes used to augment aerial releases especially when infestations occur where airspace is regulated (e.g., around airports [Penrose 1996]). In Mexico, aerial releases are limited to critical areas bordering California and Guatemala. In the interior of the country ground releases from roving vehicles are used with point releases in less accessible areas (Rull-Gabayet et al. 1996; C. Cervantes, personal communication). Although an overflooding ratio of 100 sterile to 1 feral fly in the trap-back monitoring is a standard goal (Holler et al. 1984, Buchinger 1996), there is no scientific evidence that eradication will ensue at this threshold and the actual rate of release is almost always governed by the availability of sterile flies (Penrose 1996). Program management requires the allocation of resources to the most efficacious strategy. Such decisions require basic knowledge on the performance of the insects after release, as well as knowledge of the dynamics of the target population. At present this knowledge is far from perfect.

\section{Acknowledgments}

The authors gratefully acknowledge the diligent efforts of Miguel Robles, Ronay Riley, Celestino Cervantes, Francisco Daniel, Jose Galvan, and Reyes Garcia for collection, assortation, and identification of the insect material in the traps. We also are indebted to Señores Ruben Bravo, Manuel Juarez-Camacho, Carlos Evangelista, Asuncion De Leon, and Pablo Livas-Villareal for access to their properties. Regina Suguyama (University of Sâo Paulo), Timothy Holler 
(USDA-APHIS), and Nancy Epsky (USDA-ARS) reviewed the manuscript. The sterile flies and information on the status of the Rio Grande valley sterile release and trapping program were provided by USDA-APHIS personnel, notably John Worley and Bob Vlasik. This research was conducted under the authorization of the Dirección General de Sanidad Vegetal SARH, Campaña Nacional Contra Moscas de la Fruta and the cooperation of the Comité Estatal de Sanidad Vegetal, Nuevo Leon.

\section{References Cited}

Aluja, M. 1994. The study of movement in tephritid flies: review of concepts and recent advances, pp. 105-113. In M. Aluja and P. Liedo [eds.], Fruit flies: biology and management. Springer, New York.

Aluja, M., H. Celedonio-Hurtado, P. Liedo, M. Cabrera, F. Castillo, J. Guillen, and E. Rios. 1996. Seasonal population fluctuations and ecological implications for management of Anastrepha fruit flies (Diptera: Tephritidae) in commercial mango orchards in southern Mexico. J. Econ. Entomol. 89: 654-667.

Arbingast, S. A., C. P. Blair, J. R. Buchanan, C. C. Gill, R. K. Holz, C. A. Marin, R. H. Ryan, M. E. Bonine, and J. P. Weiler. 1975. Atlas of Mexico. University of Texas Press, Austin

Baker, P. S., and A.S.T. Chan. 1991. Appetitive dispersal of sterile fruit flies: aspects of the methodology and analysis of trapping studies. J. Appl. Entomol. 112: 263-273.

Baker, P. S., A.S.T. Chan, and M. A. Jimeno-Zavala. 1986. Dispersal and orientation of sterile Ceratitis capitata and Anastrepha ludens (Tephritidae) in Chiapas, Mexico. J. Appl. Ecol. 23: 27-38.

Buchinger, D. 1996. Action Programs: California industry comments, pp. 531-532. In B. A. McPheron and G. A Steck [eds.], Fruit fly pests: a world assessment of their biology and management. St. Lucie, Delray Beach, FL.

Carey, J. R. 1993. Applied demography for biologists, with special emphasis on insects. Oxford University Press, $\mathrm{Ox}$ ford, England.

Celedonio-Hurtado, H., P. Liedo, M. Aluja, J. Guillen, D. Berrigan, and J. Carey. 1988. Demography of Anastrepha ludens, A. obliqua and A. serpentina (Diptera: Tephritidae) in Mexico. Fla. Entomol. 71: 111-120.

Celedonio-Hurtado, H., M. Aluja, and P. Liedo. 1995. Adult population fluctuations of Anastrepha species (Diptera Tephritidae) in tropical orchard habitats of Chiapas, Mexico. Environ. Entomol. 24: 861-869.

Deevey, E. S. 1947. Life tables for natural populations. Quart. Rev. Biol. 22: 283-314.

Dickens, J. C., E. Solis, and W. G. Hart. 1982. Sexual development and mating behavior of the Mexican fruit fly, Anastrepha ludens. Southwest. Entomol. 7: 9-15.

Dobzhansky, T., and S. Wright. 1943. Dispersion rates in Drosophila pseudoobscura. Genetics 28: 304-340.

Eskafi, F. M. 1988. Infestation of citrus by Anastrepha spp. and Ceratitis capitata (Diptera: Tephritidae) in high coastal plains of Guatemala. Environ. Entomol. 17: 52-58.

Fletcher, B. S. 1974. The ecology of a natural population of the Queensland fruit fly, Dacus tryoni V. The dispersal of adults. Aust. J. Zool. 22: 189-202.

Fletcher, B. S., and A. P. Economopoulos. 1976. Dispersal of normal and irradiated laboratory strains and wild strains of the Olive fly Dacus oleae in an olive grove. Entomol Exp. Appl. 20: 183-194.

Freeman, G. H. 1977. A model relating numbers of dispersing insects to distance and time. J. Appl. Ecol. 14: 477-487.
Hawkes, C. 1972. The estimation of dispersal rate of the adult cabbage root fly (Erioischia brassicae (Bouche)) in the presence of a brassica crop. J. Appl. Ecol. 9: 617-632.

Holler, T. C., J. L. Davidson, A. Suarez, and R. Garcia. 1984 Release of sterile Mexican fruit flies for control of feral populations in the Rio Grande Valley of Texas and Mexico. J. Rio Grande Valley Hortic. Soc. 37: 113-121.

Holler, T. C., and D. L. Harris. 1993. Efficacy of sterile release of Anastrepha suspensa adults against wild populations, pp. 329-333. In M. Aluja and P. Liedo [eds.], Fruit flies: biology and management. Springer, New York.

Lawson, F. R. 1967. Theory of control of insect populations by sexually sterile males. Ann. Entomol. Soc. Am. 60: 713-722.

Martinez, A. J., T. C. Holler, and J. N. Worley. 1987. A fructose and yeast hydrolysate diet for the irradiated Mexican fruit fly adult, Anastrepha ludens (Loew), and its effect on male longevity. Southwest. Entomol. 12: 317320.

McPhail, M. 1937. Relation of time of day, temperature and evaporation to attractiveness of fermenting sugar solution to Mexican fruitfly. J. Econ. Entomol. 30: 793-799.

Penrose, D. 1996. California's 1993/1994 Mediterranean fruit fly eradication program, pp. 551-554. In B. A. McPheron and G. J. Steck [eds.], Fruit fly pests: a world assessment of their biology and management. St. Lucie, Delray Beach, FL.

Pinder, J. E., J. G. Wiener, and M. H. Smith. 1978. The Weibull distribution: a new method of summarizing survivorship data. Ecology 59: 175-179.

Plant, R. E., and R. T. Cunningham. 1991. Analyses of the dispersal of sterile Mediterranean fruit flies (Diptera: Tephritidae) released from a point source. Environ. Entomol. 20: 1493-1503.

Plummer, C. C., M. McPhail, and J. W. Monk. 1941. The yellow chapote, a native host of the Mexican fruit fly. U.S. Dep. Agric. Tech. Bull. 775.

Rudd, W. G., and R. W. Gandour. 1985. Diffusion model for insect dispersal. J. Econ. Entomol. 78: 295-301.

Rull-Gabayet, J. A., J. Reyes-Flores, and W. Enkerlin-Hoeflich. 1996. The Mexican national fruit fly eradication campaign: largest fruit fly industrial complex in the world, pp. 561-563. In B. A. McPheron and G. A. Steck [eds.], Fruit fly pests: a world assessment of their biology and management. St. Lucie, Delray Beach, FL.

Schroeder, W. J., R. T. Cunningham, R. Y. Miyabara, and G. J. Farias. 1972. A fluorescent compound for marking Tephritidae. J. Econ. Entomol. 65: 1217-1218.

Shaw, J. G., M. Sanchez-Riviello, L. M. Spishakoff, P. TrujilloG., and F. Lopez-D. 1967. Dispersal and migration of tepa-sterilized Mexican fruit flies. J. Econ. Entomol. 60: 992-994.

Sokal, R. R., and F. J. Rohlf. 1973. Introduction to biostatistics. Freeman, San Francisco. Speakeasy Computing. 1987. Speakeasy manual. Speakeasy Computing, Chicago, IL.

Taylor, R.A.J. 1978. The relationship between density and distance of dispersing insects. Ecol. Entomol. 3: 63-70.

1980. A family of regression equations describing the density distribution of dispersing organisms. Nature (Lond.) 286: 53-55

Thomas, D. B. 1993. Survivorship of the pupal stages of the Mexican fruit fly, Anastrepha ludens (Loew) (Diptera: Tephritidae), in an agricultural and non-agricultural situation. J. Entomol. Sci. 28: 350-362.

1997. Degree-day accumulations and seasonal duration of the pre-imaginal stages of the Mexican fruit fly (Diptera: Tephritidae). Fla. Entomol. 80: 71-79. 
Williamson, D. L., and W. G. Hart. 1989. Current status of Mexican fruit fly research in the Rio Grande Valley of Texas, pp. 563-569. In R. Cavalloro [ed.], Fruit flies of economic importance 87. Balkema, Rotterdam, The Netherlands.
Wadley, F. M. 1957. Some mathematical aspects of insect dispersion. Ann. Entomol. Soc. Am. 50: 230-231.

Received for publication 2 December 1997; accepted 27 April 1998. 